\title{
DEMOGRAPHY, NATIONAL SAVINGS AND INTERNATIONAL CAPITAL FLOWS
}

\author{
By MATTHEW HigGINS ${ }^{2}$
}

This paper addresses the relationship between age distributions, national savings and the current account balance. The results point to substantial demographic effects, with increases in both the youth and old-age dependency ratios associated with lower savings rates. They also point to differential effects on savings and investment, and thus to a role for demography in determining the current account balance. The estimated demographic effect on the current account balance exceeds six percent of GDP over the last three decades for a number of countries and, given expected demographic trends, is likely to be substantially larger over the coming decades.

${ }^{2}$ The author thanks Jeffrey Williamson, N. Gregory Mankiw, Jonathan Morduch, Carol Olser, the Editor and two anonymous referees for helpful comments and criticism. The views expressed in this paper are those of the author, and do not necessarily reflect the views of the Federal Reserve Bank of New York or the Federal Reserve System. 


\section{Introduction}

What role have the dramatic demographic changes of recent decades played in determining national savings and investment rates? And how will these variables - and hence the pace of capital formation—be affected by the even more dramatic changes expected for the decades to come ${ }^{3}$ This paper undertakes an econometric investigation of the links between national age distributions and savings and investment rates, drawing on time-series and cross-section data for 100 countries. The results point to substantial demographic effects, with increases in both the youth and old-age dependency ratios associated with lower saving rates. Demographic effects on national saving rates have often been quite large, exceeding seven percent of GDP over the last three decades for a number of countries. Perhaps more important, the results point to differential demographic effects on savings supply and investment demand, and thus, to a role for demography in determining the residual between the two: net capital flows or the current account balance (CAB). In particular, high youth dependency rates display a strong connection with current account deficits, with nations joining the ranks of capital exporters as they mature. The estimated demographic effect on the CAB exceeds four percent of GDP over the last three decades for many countries.

This paper is best interpreted as extending the youth-dependency thesis Coale and Hoover (1958) advanced almost forty years ago, from saving rates alone to investment and the CAB. These authors worried that high youth-dependency burdens would limit developing countries' ability to generate the savings needed to sustain domestic capital formation, and hence, economic growth. The evidence presented here suggests that, at least for many countries, access to surplus foreign savings has provided an important buffer, allowing some of the youth-dependency burden to be reflected in a lower $\mathrm{CAB}$ rather than lower domestic investment. Moreover, the evidence suggests that the youthdependency/CAB link has been strongest for nations whose policies have allowed a fairly high degree of integration into the international capital market. The finding that maturing nations tend to graduate from reliance on capital imports also has important implications for the adequacy of the global savings

\footnotetext{
${ }^{3}$ World demographic trends since 1950, and those expected up to 2025, are outlined in United Nations (1991).
} 
pool in the decades ahead. In particular, currently developing nations should prove increasingly able to finance their own investment needs - a prospect in stark contrast with the pessimistic prognosis offered by Depak Lal (1991) and others. Expected demographic trends in the currently developed world should work in the same direction, with greying populations causing investment to decline more sharply than savings, reinforcing the trend toward global capital abundance.

Section 2 reviews the dependency debate. Section 3 describes the econometric strategy and presents the empirical results, and assesses the role of economic openness in determining the strength of demographic effects on savings, investment and capital flows. Section 4 discusses the implications of the results for the direction and scale of capital flows in the early decades of the 21 st century.

\section{The Dependency Debate}

The notion that a large population of dependent young increases consumption requirements at the expense of savings enjoys a distinguished pedigree. Ansley Coale and Edgar Hoover made it a centerpiece of their seminal work, Population Growth and Economic Development in Low Income Countries (1958). Leff's (1969) study a decade later appeared to place the youth-dependency hypothesis on a sound empirical footing. But subsequent research by Goldberger (1973), Ram (1982) and others failed to confirm the dependency hypothesis, and thus cast doubt on the validity of the empirical methods employed in the earlier studies. Not long ago, Angus Deaton (1992) offered the following judgement concerning the empirical literature on demography and saving rates: “Although there are some studies that find ... demographic effects, the results are typically not robust, and there is no consensus on the direction of the effect on saving."

This skeptical assessment aside, the youth dependency hypothesis has in recent years enjoyed something of a renaissance, owing in large measure to the work of Mason and Fry (1982) and Mason alone $(1987,1988)$. These authors develop what they call a "variable rate-of-growth effect" model of the link between youth dependency and national saving rates. The new model relies on the insight which motivates the lifecycle theory of savings: given positive labor productivity growth, younger cohorts enjoy higher permanent incomes and higher consumption than their elders. The dependency and lifecyle perspectives are united by allowing changes in the youth dependency ratio to induce 
changes in the timing of life-cycle consumption. For example, a decline in the youth dependency ratio should cause consumption to be shifted from childrearing to later, non-childrearing stages of the lifecycle. As a result, according to the model, the saving rate depends on the product of the youthdependency ratio and the growth rate of national income (the "growth-tilt effect"), as well as on the dependency ratio itself (the "level effect").

The new model has enjoyed some measure of empirical success. Drawing on cross-section data for about 50 countries, Mason and Fry find solid empirical support for the model, isolating a negative relationship between youth dependency and saving rates after controlling for the interactive effects of dependency and income growth. Collins (1991) reports similar results for a smaller cross section of developing countries. Taylor and Williamson (1994) apply the model to over a century of savings behavior in Canada, Australia and Argentina, finding suggestive evidence of demographic origins for late 19th century capital flows. Taylor (1995) applies the model to Latin American savings and investment behavior since the 1960s, and considers its implications for the evolution of the region's current account balances during the early decades of the next century.

However, despite its empirical successes, the variable rate-of-growth effect model is unlikely to provide an adequate theoretical for framework for understanding the behavior of saving rates and capital flows over the course of the demographic transition. Most important, the variable rate-ofgrowth effect model describes only the steady-state relationship between dependency and saving rates-a shortcoming derived from its life-cycle ancestry. ${ }^{4}$ Yet the rapid pace of demographic change over the past half century surely supports the presumption that the observed correlation between depdendency and saving rates or capital flows owes largely to transitional dynamics. Second, the variable rate-of-growth effect model focuses exclusively on the link between dependency and saving

4 The variable rate-of-growth effect model assumes steady-state population and productivity growth (Mason 1987). Rather inconsistently, the youth dependency rate is allowed to vary, although it is simply an increasing function of steadystate population growth. Higgins and Williamson (1996) show that the model's qualitative implications remain unchanged when the correspondence between population growth and youth dependency is acknowledged. 
rates, ignoring the determinants of investment demand. Yet saving is determined independently of investment only under perfect capital mobility, that is, for a small, open economy facing an exogenous world interest rate. In any other setting, the observed saving rate depends on both domestic savings supply and investment demand. By abstracting from demographic influences on investment demand, the variable rate-of-growth effect model provides no theoretical guidance concerning the effects of demographic change on investment itself, nor concerning the residual between savings and investment: the current account balance or net capital flows.

To confront these issues, a dynamic model is required, one capable of accommodating demographic effects on both savings supply and investment demand. The required model is in fact quite simple. Higgins and Williamson (1996) show that the variable rate-of-growth effect model can be subsumed under the textbook (e.g., Blanchard and Fischer, 1988) neoclassical growth model, inhabited by an overlapping generations population: the former model is, in essence, the open-economy, steadystate version of the latter. The textbook model need only be augmented by adding a third period of life — childhood as well as maturity and old age —in order to accommodate the study of youth as well as elderly dependency effects.

The authors rely on simulations to study the economy's dynamic evolution in response to empirically plausible patterns of demographic change. (Closed-form solutions are generally unavailable, even given simple functional forms.) A simulated "demographic transition," in which fertility rises for several generations before falling to a new, lower steady-state level, provides an illuminating experiment because such a pattern roughly describes the demographic history of many nations in the current sample.

The simulation results highlight an important qualitative implication of standard growth models: the demographic "center of gravity" for investment demand should be earlier in the age distribution than that for savings supply. In particular, investment demand should be most closely related to the share of young (through its connection with labor-force growth), while savings supply should be most closely related to share of mature adults (through its connection with retirement needs). The divergence between these centers of gravity implies that the effects of demographic change on 
savings and net capital flows will depend on the economy's degree of openness to capital flows. ${ }^{5}$ For a financially open economy, a shift in the population age distribution towards younger ages should produce a tendency towards current account deficits: savings falls due to the increased dependency burden, even as investment rises in response to higher labor-force growth. As the age distribution shifts towards the center, savings supply should increase, even as investment demand slackens, pushing the current account into surplus. In contrast, for a closed economy, the younger center of gravity for investment would cause the observed (i.e., equilibrium) saving rate to appear positively related to relatively young aspects of the age distribution. ${ }^{6}$

Does the open- or closed-economy assumption provide the better framework for analyzing the observed dynamics of savings, investment and the CAB? The fact that many countries have relied heavily on capital imports might appear to create a strong prima facie case against the closed-economy assumption. $^{7}$ However, as noted by Williamson (1993), the key issue is whether investment is constrained by domestic savings. If the economy faces a binding constraint on capital inflows, equilibrium in the domestic capital market will depend on both local savings supply and investment demand. In this setting, changes in demographic dependency will alter the market outcome in a way

${ }^{5}$ For concreteness, consider perfect capital mobility (or perfect financial openness) to hold when domestic residents can borrow or lend in the international capital market at an exogenous world interest rate. A perfectly closed economy operates under financial autarky.

${ }^{6}$ Importantly, these qualitative implications do not stem from the OLG model's assumption that agents have only a limited temporal horizon, or from the model's stylized demographic structure. Cutler et al. (1990) rely on the familiar Cass-RamseySolow optimal growth model to find the social planner's solution for capital flows between the U.S. and the rest of the OECD in the decades ahead. The authors find that the U.S., with its younger population and more rapidly growing labor force, should finance part of its investment needs by running current account deficits. As the U.S. population matures (thus approaching OECD norms), the CAB should swing into surplus.

${ }^{7}$ During the 1980-1992 period, the average (unweighted) current account deficit amounted to 12.4 percent of GDP for sub-Saharan Africa, 5.4 percent of Latin America and 8.5 percent for South Asia (Bangladesh, India, Myanmar, Nepal, Pakistan and Sri Lanka). 
qualitatively similar to that which would be observed in a closed economy. For example, increased youth dependency might lower the supply of savings at a given interest rate, leading to an equal decline in savings and investment, and leaving the volume of capital inflows unchanged. However, under weaker restrictions on capital mobility, dependency rate changes should affect the equilibrium of the domestic capital market in a way which displays features of both the closed- and open-economy models. A positive link between youth dependency and capital inflows would remain, but it would be weaker than under perfect capital mobility.

\section{Empirical Perspectives}

This section studies the empirical links between national age distributions and savings, investment and the $\mathrm{CAB}$. The analysis proceeds along two complementary lines. First, it explores how these variables evolve over time in a given country in response to changing age distributions by applying panel-data techniques to time-series data available for a sample of 100 countries. Second, it explores how cross-country differences in these variables at a given time may be explained by differences in age distributions by treating the data as drawn from a single cross section. The results from the two approaches are qualitatively similar, and provide striking evidence that demographic dependency has had profound effects on savings, investment and capital flows.

(4.1.) The Time Series: Econometric Issues and Empirical Specification. The models estimated here follow the dependency literature in treating the national saving rate (as well as the other dependent variables) as functions of the population age distribution, growth in labor productivity and interactions among these variables. (See Appendix A.1 for data sources.) Following Alan Taylor (1995), I also add the relative price of investment goods to control for its possible effects on savings supply or investment demand. The resulting reduced-form estimating equations are given by:

$$
s_{i, t}=\beta_{o, i}+\boldsymbol{\beta}_{\mathbf{1}} \boldsymbol{D}_{i, t}+\beta_{2} G R O W T H_{i, t}+\boldsymbol{\beta}_{\mathbf{3}} \boldsymbol{D}_{i, t} G R O W T H_{i, t}+\boldsymbol{\beta}_{\mathbf{4}} \boldsymbol{R} \boldsymbol{P} \boldsymbol{I}_{i, t}+u_{i, t}
$$

where $s_{i, t}$ represents the dependent variable (measured as a share of nominal GDP) in country $i$ at time $\mathrm{t}, \mathbf{D}_{\mathrm{i}, \mathrm{t}}$ refers to a vector of demographic variables, GROWTH $\mathrm{G}_{\mathrm{i}, \mathrm{t}}$ is the growth of labor productivity and $\mathbf{R P I} \mathbf{I}_{\mathrm{i}, \mathrm{t}}$ represents the relative price of investment goods. 
$\mathbf{D}_{\mathrm{i}, \mathrm{t}}$ is constructed by using a low-order polynomial to represent 15 population age shares: 0-4, $5-9, \ldots, 65-69$ and $70+$. This technique for incorporating demographic information into macroeconomic equations was introduced by Fair and Dominguez (1991), and has the advantage of capturing the information contained in the entire age distribution while maintaining a parsimonious parameterization (Appendix A.2). To see how the technique works, consider replacing $\mathbf{D}_{\mathrm{i}, \mathrm{t}}$ in equation (1) with the population age shares. A simple F-test for the significance of the 14 included age shares (one being omitted because they sum to unity) could then be used to test the general proposition that "age structure matters." However, because the various elements of the age distribution are highly correlated, the regression results would be plagued by multicollinearity, making it difficult to isolate the contribution of any particular element. The dependency literature deals with this problem by estimating age coefficients for one or at most two age shares.

The polynomial representation employed here implies a less restrictive approach. First, I require that the 15 age-distribution coefficients, ${ }_{1}, \ldots,{ }_{15}$, sum to zero. Second, I require that they lie along a low-order polynomial. ${ }^{8}$ In the cubic case, for example, we have:

$$
j=0^{+} j_{1}+j^{2} 2^{+} j^{3} \quad(j=1, \ldots, 15)
$$

Given the zero restriction, there are now only three independent population coefficients to estimate $\left({ }_{1}\right.$, ${ }_{2}$ and $\left.{ }_{3}\right)$. Constraining the ${ }_{j}$ in this fashion leads to the construction of three new variables $\left(D 1, D_{2}\right.$ and $\mathrm{D}_{3}$ ), which are complicated geometric averages of the population age shares. Although the estimated coefficients of the new variables have no direct structural interpretation, the implicit age distribution coefficients (the ${ }_{j}$ ) are easily recovered (Appendix A.2).

In order to mitigate the strong serial correlation likely to characterize national savings or

${ }^{8}$ The ${ }_{j}$ must be restricted to sum to zero because the population age shares sum to unity, and thus are collinear with the intercept term. This restriction implies that the constant term is not affected if the age distribution does not affect the dependent variable. The restriction that the ${ }_{j}$ lie along a low-order polynomial implies that the relationship between savings (or investment) and the population age shares changes smoothly. 
investment rates, the data are measured as five-year averages, with the years from 1950 to 1989 divided into eight periods. To control for any remaining serial correlation, the estimated standard errors are corrected using the technique introduced by Newey and West (1987). The standard errors are also corrected for contemporaneous heteroskedasticity.

The models estimated here are of the "fixed-effects" variety: the intercept term is allowed to vary across countries, while the slope coefficients are treated as common to all countries. This procedure in effect transforms the data into deviations from country-specific means, leaving only the time-series variation in the data, and has the advantage of controlling for persistent unmodelled factors which affect the average value of the savings or investment rate in a particular country. Standard tests easily reject the null alternatives of the "random-effects" and common-intercept specifications. ${ }^{9}$ Even so, focusing only on the temporal variation in the data may sacrifice important information. In particular, it is of interest to know whether age structure helps to explain the cross-sectional distribution of saving rates, investment rates and CABs, as well as secular trends within a given country. To address this issue, I estimate separate regressions below for the international cross section.

A final issue concerns whether the model parameters can be consistently estimated by ordinary least squares. Simultaneity bias might arise, for example, because savings and growth rates are subject to common shocks over the course of the business cycle. A high saving rate might also raise the supply of investment goods, lowering their relative price-a possibility which finds empirical support in DeLong and Summers (1991). Unfortunately, experimentation with various candidate instruments

\footnotetext{
${ }^{9}$ I rely on the Hausman test (Greene, 1993, pp. 479-480) to choose between the random-effects and fixed-effects specifications. Under the null, the random effects estimates are unbiased and efficient, while the fixed effects estimates are unbiased but inefficient. Under the fixed effects alternative, the random-effects estimates are biased. The results point to substantial bias: the random-effects null is rejected at the one-percent level for the national savings and investment equations, and at the five-percent level for the $\mathrm{CAB}$ equation. Simple Chow tests reject the null alternative of the common intercept specification at the one-percent level for the savings and investment equations, and at the five-percent level for the $\mathrm{CAB}$ equation.
} 
failed to yield a set which appears uncorrelated with the equation errors. ${ }^{10}$ As a result, the models are estimated using ordinary least squares. Monte Carlo experiments, described below, suggest that a type II error (incorrect rejection of the non-demographic null) is likely only given a specific, and fairly strong, pattern of correlation between the possibly endogenous variables and the equation errors. (4.2) Fixed-Effects Estimation Results. The fixed-effects estimates point to powerful demographic effects on national savings, investment and the current account balance (Table 1). For all three equations, the demographic variables are jointly significant at the one-percent level under the benchmark specification, which does not include interactive terms. ${ }^{11,12}$ Table 1 also shows the implied age-distribution coefficients, surrounded by 90 -percent confidence intervals. ${ }^{13}$ The estimates for national savings imply a relatively weak youth-dependency effect, with a significant negative coefficient (relying on a five-percent, one-sided test) only for the first period of life (0-5). More generally, the age coefficients appear to describe the "hump" pattern predicted by the life-cycle hypothesis. But they reach a peak rather early, during the seventh period of life (30-34), decline sharply after the 10th period

${ }^{10}$ I rely on a standard Lagrange multiplier test, described by Davidson and MacKinnon (1993), pp. 232-237. The test is implemented by regressing the 2SLS residuals on the set of instruments. Under the null of instrument exogeneity, the number of observations multiplied by the uncentered $\mathrm{R}^{2}$ is distributed as a ${ }^{2}$ with degrees of freedom equal to the number of overidentifying restrictions. The exogeneity of the chosen instrument set is crucial: recent research suggests that the degree of inconsistency of 2SLS may exceed that of OLS given even a small degree of endogeneity (Shea, 1996).

${ }^{11}$ Estimates for all three equations are reported only for the reader's convenience. One of the equations is redundant, due to the fact that the $\mathrm{CAB}$ is linked to savings and investment according to the identity, $\mathrm{CAB}=\mathrm{S}-\mathrm{I}$, and the fact that the three variables are regressed on a common information set.

${ }^{12}$ Initial tests revealed that a cubic polynomial is required to capture demographic effects for the investment and CAB equations. Although demographic effects on national savings are adequately captured by a quadratic polynomial, a cubic specification was chosen to ensure that estimates for the three equations remain mutually consistent. The "overfitting" of the savings equation appears harmless, as the cubic and quadratic age-distribution coefficients are very similar.

13 The standard errors associated with the age-distribution coefficients are derived from the estimated parameter covariance matrix using the “delta method” (Greene, 1993, pp. 297-299). 
(45-49) and turn negative by the 12th (55-59). However, the negative coefficients are statistically significant only for ages 60 and higher; and the upper bound of the 90 percent-confidence interval leaves room for the possibility that the depressing effect of aging on savings is much weaker than indicated by the point estimates.

It is also important to note that the negative coefficients for the elderly need not indicate that they are actually drawing down their stocks of assets. The burden of supporting the elderly (either directly or through transfer payments) might lead to lower saving by younger households. Alternatively, prime-age households with elderly parents might save less in anticipation of bequest receipts (Weil, 1994). The age coefficients are not behavioral parameters which describe the actions of agents belonging to different age groups, but instead capture the relationship between the age distribution and the behavior of agents of all ages. Thus, there is no way to choose among these explanations for the pattern of the age coefficients on the basis of the results reported here.

Productivity growth is also estimated to have a strong, positive effect on the saving rate, in line with the implications of almost any theory of savings behavior. The coefficient for the relative price of investment goods is positive, but small and statistically insignificant. However, the estimated coefficient does imply that higher investment prices depress the real saving rate, where this is defined as S/RPI. ${ }^{14}$ In what follows, I generally confine discussion to the estimated demographic effects.

The age distribution coefficients for investment are strongly concentrated at the younger tail of the age distribution, reaching a peak by ages $15-19$, and turning negative by ages $40-44$. This pattern is in accord with the intuition that investment demand should be closely linked to labor-force growth, and with the intuition that young, growing populations should require greater additions to social overhead capital. The positive coefficient for the last period of life (70+) is not statistically significant; indeed, we cannot reject the null hypothesis that the age distribution coefficients remain flat after age 60 .

\footnotetext{
${ }^{14}$ There are in fact few theoretical results concerning the effect of relative investment prices on savings or investment. Indeed, abstracting from expected capital gains, any model which posits a role for real interest rates in determining these variables can be rewritten with terms involving $(1+r)$ replaced by $(1+r) / R P I$.
} 
For the $\mathrm{CAB}$, the age distribution coefficients are negative and fairly large for roughly the first third of life (ages 0-24). Indeed, the negative link between youth dependency and the CAB appears much stronger than the savings/youth-dependency link emphasized in the earlier literature. This result points to a differential impact of youth dependency on savings and investment, with large young populations depressing savings supply while augmenting investment demand. The coefficients are large and positive during the broad middle of life (ages 35-59), when households should be in their high-saving years, but demographic pressure on investment demand (via labor-force growth) should have faded. Saving appears to decline more than investment as the population ages: the agedistribution coefficients turn negative by age 65 . However, this effect is statistically significant only for the last period of life (ages 70+).

[Table 1 about here.]

With the results for investment and the current balance in hand, we can reconsider the rather young "center of gravity" found for the saving rate (say, ages 15 to 49). In particular, this result is what might be expected if international capital markets are imperfectly integrated. Savings supply and investment demand are separately identified in the empirical models developed here only to the extent that countries can borrow and lend on the international capital market without constraint and at a given world interest rate. In the absence of perfect capital mobility, the estimates for savings will reflect a mix of the separate demographic influences on both savings and investment - a lesson made clear by the simulation model developed above. In this setting, an increase in the share of younger adults, who presumably save little, might lead to an increase in equilibrium quantity of savings by causing an outward shift in the investment demand schedule. Similarly, an increase in the ranks of late middleaged would be associated with a reduction in savings if any outward shift in savings supply is more than offset by an inward shift in investment demand. I return below to the possibility that the differential effects of demographic change on savings supply and investment demand will appear sharper for relatively open economies.

As noted above, the variable-rate-of-growth effect model implies that savings depends on the youth-dependency ratio itself, and on the product of the youth-dependency ratio and the steady-state 
rate of income growth. In the spirit of this model, regressions were also estimated which included interactions between the demographic variables and productivity growth. The results appear to provide some support for the model: the interactive terms are significant at the two-percent level for national savings, and at the eight-percent level for investment. For the CAB, however, the interactive terms fell well short of significance at the 10-percent level. However, the coefficient estimates are not in accord with the qualitative implications of the model: the interactive effects point to a positive growth-tilt relationship between youth dependency and savings. Moreover, as is evident from Table 2, the interactive effects are fairly small even at high productivity growth rates. (The growth rate of 5.5 percent is the average over the 1955-59 to 1985-89 period for the top five countries.) As for the investment equation, the interactive effects, although marginally statistically significant, are paltry in quantitative terms.

[Table 2 about here.]

In interpreting these results, it is helpful recall a point stressed earlier: namely, that the variable rate-of-growth effect model concerns the steady-state relationship between youth dependency and savings. The fixed-effects model considered here is explicitly dynamic; and thus, the empirical results do not directly bear on the variable rate-of-growth effect model. Given the mixed evidence for interactive effects, as well as the absence of a clear basis for in theory for such effects, I will treat the non-interactive model as representing the benchmark specification. In particular, I will rely on it to assess the likely effects of demographic change on savings, investment and capital flows over the early decades of the 21 st century. Even so, these results should not be construed as offering conclusive evidence that interactive effects are unimportant.

(4.3) Quantitative Implications. The results presented above indicate that demographic effects on savings, investment and the current balance are significant in statistical terms. The larger, and more important, question is whether they are important in economic terms. Put simply, are the demographic effects large enough to care about?

In fact, the estimated demographic effects are often quite large. For a given period, the demographic effect on a country's saving rate can be defined as the demographically-induced deviation 
from the country's average saving rate over the sample period. The demographic effect is calculated by summing over the products of (1) the deviations of the age shares from their country-specific means and (2) the corresponding age-distribution coefficients. The difference in this demographic effect between any two periods - the "demographic swing”—gives the change in a country's saving rate induced by changes in its age distribution.

Table 3 shows the demographic swing in saving rates and the $\mathrm{CAB}$ for 15 countries, chosen to represent various regions and levels of economic development. ${ }^{15}$ For the developed world, the most dramatic dependency effects appear to have occurred in Japan. Over the next three decades spanning 1950-54 to 1980-84, Japan's youth dependency ratio fell by an astonishing 12 percentage points, accompanied by an almost equal increase in the prime-age share. The result, according to the estimates, was a positive demographic swing in Japan's saving rate amounting 5.6 percent of GDP. The demographic boost to Japan's saving rate has since begun to fade, as a rapid climb in elderly dependency has outweighed further declines in youth dependency.

The estimates point to somewhat less powerful demographic effects elsewhere in the developed world. In the U.S., for example, the greatest negative pressure on the saving rate occurred during 1960-64, when the youth dependency ratio reached its post-war peak. By 1985-89, the youthdependency ratio had declined by more than eight percentage points, accompanied by a slight increase in the prime-age share. The result, according to the estimates, was a positive demographic swing of 2.5 percentage points in the U.S. saving rate. Apparently, the tendency for savings to increase was muted by a rising elderly share. (This result highlights the obvious fact that demography is not everything: over the period in question, the U.S. saving rate in fact fell by four percentage points.) In the

\footnotetext{
${ }^{15}$ For each country, the period shown contains the greatest demographic swing in the saving rate. The same period does not in general contain the greatest demographic swing in the CAB. For the 23 OECD countries in the sample, the average maximum demographic swing (in absolute value) amounted to 2.4 percent of GDP for national savings, 3.2 percent for investment and 3.6 percent for the CAB. For the 77 non-OECD countries, the corresponding figures are 4.5 percent for savings, 3.3 percent for investment and 3.2 percent for the CAB.
} 
developing world, demographic effects on savings appear to have been most dramatic for Korea and other Pacific Rim countries. The estimates imply a favorable demographic swing of more than 10 percentage points between 1960-64 and 1985-89, a period which saw a decline of more than 14 percentage points in Korea's youth-dependency ratio, and an increase of 9.6 percentage points in her prime-age share. If estimates are correct, demographic change is responsible for more than half of the increase in Korea's saving rate over this period. In Latin America, the pace of demographic transition has also been rapid, albeit less so than along the Pacific Rim. In Brazil, for example, the youth dependency ratio fell by almost eight percentage points between 1960-64 and 1985-89, while the prime-age share climbed by four percentage points. The result, according to the model, has been a demographic boost of 5.4 percent to Brazil's saving rate.

Demographic developments in Kenya, and many other countries in sub-Saharan Africa, offer a stark contrast with those just described. In recent decades, Kenya's birthrate has been among the highest in the world. As a result, the share of young has risen steadily, from 40.7 percent in 1950-54 to more than 50 percent by $1985-89$. Over the same period, the prime-age share fell by over eight percentage points, to a mere 26.2 of the population. The estimated effect is a negative swing of more than 11 percent in Kenya's saving rate. India presents a contrast of a different sort. Over the sample period, her demographic structure has been fairly stable, with the youth dependency ratio remaining at about 40 percent over 1950-64, before declining slowly to 37.2 percent in 1985-89. Thus, demographic change appears to have had little effect on India's saving rate, with a positive swing of only 1.8 percentage points between $1965-69$ and 1985-89. A relatively stable (albeit high) youth dependency ratio and modest demographic effects also characterize Nigeria and a few additional countries in sub-Saharan Africa.

The estimated demographic effects on the $\mathrm{CAB}$ follow the same general pattern as those for savings, with declining youth dependency generating a favorable demographic swing. For example, the sharp shift in Korea's age distribution towards the center is estimated to have brought an increase of 5.4 percent in the CAB between 1960-64 and 1985-89. In contrast, negative demographic pressure on the $\mathrm{CAB}$ intensified through the sample period for several countries where youth dependency rates 
have continued to rise or have only recently peaked.

[Table 3 about here.]

(4.4) The Cross-Section: Econometric Issues and Empirical Specification. As noted earlier in this essay, a fixed-effect panel model exploits only the time-series variation in the data, confining attention, e.g., to the relationship between changes in a given country's age distribution and changes in its saving rate. But differences among countries in age distributions are even more profound than the changes witnessed within a given country over time. For example, although the elderly already represent more 15 percent of Germany's population, they make up less than three percent of that of Sub-Saharan Africa. The corresponding figures for the share of young present an equally striking contrast, at 15 percent and 46 percent, respectively. If age distributions matter for the evolution of saving rates and capital flows within a given country, they should leave their mark on the cross-section data as well.

The principal question concerns the right way to exploit the cross-sectional variation in the data. Given a long sample (such as the 39 years of data available for some countries here), and the rapid pace of demographic change in many countries, a country's average age distribution over the entire sample may contain relatively little information about demographic influences on its average saving rate. For this reason, Mason (1988) divides a 20-year sample into three overlapping 10-year periods, measuring variables as period averages, in his study of dependency effects on savings. Collins (1991) averages data over five-year periods in her study of savings behavior in a group of 10 developing countries. However, both studies may count essentially the same information twice, as data concerning the age distribution generally come from decennial censuses, with figures for the intervening years filled in through linear interpolation. The level of temporal aggregation should not be so high as to destroy the information contained in the age distribution, but also high enough to ensure that the pooled regression results are driven by cross-sectional, rather than temporal, variation.

With this in mind, I measure the data as 13-year averages for the periods 1954-66, 1967-79 and 1980-92. Thus, no country contributes more than three observations. At least eight years of data for all relevant variables were required for in order for a country to contribute an observation for a given 13-year period. Period dummies are added to the model to remove any remaining temporal variation 
from the data. As before, the estimated standard errors are corrected for heteroskedasticity.

(4.5) Pooled Estimation Results. The pooled estimates point to powerful demographic effects on national savings, investment and the $\mathrm{CAB}$ (Table 4). For all three equations, the demographic variables are jointly significant at the one-percent level under the benchmark specification. The implicit age-distribution coefficients (shown surrounded by 90-percent confidence intervals) are in general quite similar to those obtained for the time-series, fixed-effects model. For example, identify nearly the same period of life as the source of peak positive pressure on savings (35-39 here vs. 30-34 earlier), and turn negative at the nearly the same period (60-64 vs. 55-59). The pooled model also yields similar youthdependency effects, and implies only a slightly stronger negative effect of elderly dependency on savings. The estimated age-distribution coefficients for investment and the $\mathrm{CAB}$ are also much like their fixed-effects counterparts, in both qualitative and quantitative terms.

The main point of discrepancy between the two models concerns relative investment prices. Under the pooled model, an increase in RPI is estimated to bring fairly sizeable reductions in both savings and investment; under the fixed-effects model, an increase in RPI is estimated to bring higher (nominal) savings and investment. The coefficient estimates from the time-series and pooled regressions should have the same expected values provided that the underlying relationship between the dependent and explanatory variables is linear, and the models are otherwise properly specified (Hsiao, 1986). I can offer no way of determining which set of results, if either, is correct. ${ }^{16}$

[Table 4 about here.]

I also estimated alternative specifications incorporating interactive effects, that is, the products of the demographic variables and labor productivity growth. These results provide only modest support for the variable rate-of-growth effect model. The interactive effects are significant at the fivepercent only in the investment equation (Table 5); the marginal significance levels for the savings and

\footnotetext{
${ }^{16}$ To the extent that any feedback from savings or investment to RPI owes to a relationship between the average values of these variables, the estimated coefficient of RPI will be biased under the pooled model, and unbiased under the fixedeffects model. (Under the same conditions, random-effects estimates would also be biased.)
} 
CAB equations exceed 10 percent (.183 and .116, respectively). Moreover, the estimated interactive effects for investment are fairly small in quantitative terms.

[Table 5 about here.]

(4.6) Economic Openness. For an economy closed to capital flows, savings and investment must be equal, and demographic change can by definition have no effect on the CAB. The open- and closedeconomy simulation reported in Higgins and Williamson (1996) also raise the intriguing possibility that demographic effects on saving rates might be larger in magnitude for relatively open economies. ${ }^{17}$

Unfortunately, there is no generally accepted metric for assessing an economy's degree of openness to capital flows. (For a cogent survey of the issues, see Obtsfeld, 1994.) Clearly, an important dimension of openness is the absence of binding explicit restrictions on capital flows. However, a country's perceived creditworthiness depends importantly on other factors, including its macroeconomic and trade policies and degree of political stability. I rely here on the summary measure of openness developed by Sachs and Warner (1995). An economy is considered closed if it is characterized by any of the following conditions: (i) a black market premium of 20 percent or more for foreign exchange; (ii) an export marketing board which appropriates most foreign exchange earnings; (iii) a socialist economic system; (iv) extensive non-tariff barriers on imports of intermediate and capital goods.

Of the above criteria, the black market premium is generally the decisive one, by itself identifying the vast majority of countries considered closed. A high black market premium should generally imply that a country is rationed in the international capital market: both foreign direct investors and domestic borrowers face immediate capital losses should the overvaluation of the official exchange rate ever be corrected. The other criteria convey important information about a country's creditworthiness, but also are usually associated with an overvalued currency and foreign exchange restrictions. Alternative measures of openness are discussed briefly below.

17 This implication is not unique to the model used there, but rather, stems from the fact that shocks to savings or investment are accommodated at an unchanged interest rate for a small, open economy. 
Allowing differential demographic effects for relatively open and relatively closed economies yields rather striking results (Table 6). ${ }^{18}$ For the open economies, the demographic variables are significant at the 1-percent level in all three equations. For the closed economies, the demographic variables remain significant at the 1-percent level for savings and investment, but fall far short of significance at the 10-percent level for the $\mathrm{CAB}$-indeed, the 90-percent confidence interval for the age-distribution coefficients (not shown) always contains zero. Thus, for closed economies, age structure appears to affect the saving rate only through investment, with no impact on the CAB. Moreover, we can reject the hypothesis of equal demographic effects for open and closed economies for savings and the $\mathrm{CAB}$ at the 5-percent level, but cannot reject the corresponding hypothesis for investment at even the 10-percent level.

The contrast in the character of the estimated demographic coefficients is equally impressive. Most obviously, the estimated demographic effects are far more powerful in quantitative terms for the open economies, especially for savings and the $\mathrm{CAB}$. Note in particular the strong depressing effect of youth dependency on savings for open economies, and the almost complete absence of such an effect for closed economies. The relative similarity of the investment coefficients for the first third of the age distribution indicates that open economies have been able to meet any dependency-induced decline in savings through increased capital inflows, rather than reduced domestic capital formation.

It is also instructive to consider the age shares associated with peak saving rates for the two sets of countries. For open economies, the greatest positive demographic pressure on savings is associated with age 40-44, and fairly sizeable positive coefficients are found for ages $25-59$. For closed economies, the greatest positive upward pressure is associated with ages 20-24, and sizeable positive coefficients are found for ages 10-34. As noted earlier, in the absence of perfect capital mobility, the

\footnotetext{
${ }^{18}$ Because Sachs and Warner classify relatively few countries as continuously open for a period long enough to derive sensible fixed-effects (time-series) estimates, I rely here on pooled data. An economy is classified as relatively open during a given 13-year period if the average value of the Sachs-Warner measure is greater than 0.5. This left 100 observations for open economies and 144 for closed economies.
} 
observed (equilibrium) saving rate will reflect a mix of the separate demographic influences on savings supply and investment demand. As a result, for closed economies, the observed saving rate should be more closely tied to the determinants of investment demand, and in particular, to labor force growth. For open economies, the observed saving rate should be more closely tied to the determinants of savings supply, and in particular, to anticipated retirement needs. The finding of divergent demographic centers of gravity for open and closed economies lends support to these theoretical conjectures concerning demography, openness and saving rates. ${ }^{19}$

\section{[Table 6 about here.]}

These results concerning economic openness, although intriguing, should be interpreted with caution. The Sachs-Warner variable, after all, is hardly the only possible measure of openness; indeed, the authors intended it as a measure of openness to trade, not capital flows. As a check on the robustness of the results just reported, I used measures of direct restrictions on capital flows to classify economies as relatively open or closed. ${ }^{20}$ This exercise proved disappointing: the demographic effects were statistically indistinguishable and of similar magnitude for the two groups of countries. However, direct measures of restrictions on capital flows may provide a poor gauge of true openness. After all, the restrictions may not be binding, or may not be vigorously enforced. Perhaps for this reason, the

${ }^{19}$ The results reported above are sharpened when real per capita income (at purchasing power parity) is added to the regression equation. The demographic variables are not significant at the 10-percent level in any of the three equations for the closed economies, but always remain significant at the one-percent level and of similar magnitude for the open economies. Thus, the Sachs-Warner openness variable is evidently not merely acting as a proxy for per capita income.

${ }^{20}$ The IMF records four policies restricting capital flows: (1) separate exchange rates for capital account transactions, (2) payment restrictions for current transactions, (3) payment restrictions for capital transactions, and (4) mandatory surrender of export proceeds. I classified an economy as relatively closed when two or more of these policies were in place. This left a total of 67 observations for open and 102 observations for closed economies. My thanks to Leonardo Bartolini and Alan Drazen for providing a tabulation of the IMF data. 
new openness variable often classifies countries in a rather counterintuitive manner. ${ }^{21}$ Even so, the negative results using the alternative openness measure highlights the need for further research. (4.7) Can We Trust the Empirical Results? An important source of the controversy surrounding dependency effects on savings is the possible fragility of the econometric estimates (Goldberger, 1973; Ram, 1982; Deaton, 1992). The issue of robustness is especially pressing for this study, which has extended the traditional dependency argument to investment and net capital flows. In order to determine whether the empirical results presented above are indeed robust, I proceeded along two lines. First, I examined whether the estimates are driven by outliers, deleting various sets of influential observations from the sample (Davidson and MacKinnon, 1993, pp. 32-39). For the fixed-effects model, for all three equations, 10 countries responsible for the most influential observations were deleted from the sample, one at a time and all at once. For the pooled model, I excluded the 10 most influential observations, in similar permutations. The estimates do not appear to be driven by outliers: the demographic variables always remain significant at the one-percent level, with the age-distribution coefficients unchanged in qualitative terms.

Second, I examined the sensitivity of the demographic effects to changes in model specification, relying on the "extreme-bounds" analysis (EBA) developed by Leamer (1983), and employed by Levine and Renault (1992) in their influential study of the robustness of cross-country growth regressions. EBA begins with a benchmark model which expresses the empirical relationship under scrutiny. Various alternative regressors are then added, singly or a few at a time. An empirical relationship is considered robust if the relevant parameters are of the expected sign and statistically significant under each permutation. To implement EBA, I chose several variables available for a large

${ }^{21}$ The data cover 1966-1992. The following are some of the countries classified as always closed: Chile, Korea, Thailand, Spain and Portugal. Other counterintuitive classifications include; Australia, closed before 1983; BelgiumLuxembourg, closed 1966-67 and 1977-90; Denmark, closed before 1988; France, closed 1968-92; Norway, closed 196670 and 1973-92; Singapore, closed 1966-79; UK, closed 1966-80. 
number of countries which are plausible determinants of national savings or investment rates. ${ }^{22}$ Following Levine and Renault, the new regressors were added to the estimating equations in every possible set of three. The link running from demography to saving rates, investment and net capital flows is evidently quite robust: the demographic variables remained significant at the one-percent level under every permutation, with no qualitative change in the age-distribution coefficients.

A remaining issue, broached earlier, is whether the apparently significant demographic effects owe instead to simultaneous-equations bias. In order to assess the likelihood that a type II error might arise from this source, I conducted a series of Monte Carlo experiments. The experiments were implemented by searching over the potential patterns of correlation between the possibly endogenous variables (GROWTH and RPI) and the underlying equation errors. ${ }^{23}$

${ }^{22}$ For the fixed-effects model, EBA was implemented using the following variables: the black market premium for foreign exchange; the average annual rate of inflation; the ratio of the liquid liabilities of the financial system to GDP; the average human capital stock, as measured by the average educational attainment of the population over age 25 ; terms of trade shocks, as measured by the difference between GDP growth at current and constant trade prices; the real yield on U.S. government 10-year bonds, measured using the U.S. inflation rate; and time dummies for each period. For the pooled model, where the data are measured as 13-year averages, I was able to add several variables which show little time-series variation, or are not I(0). These included real output per worker, measured at 1985 international prices; average economic openness, as measured by Sachs and Warner; and the incidence of direct foreign exchange controls, as complied by the IMF. For the pooled model, I was also able to add the within-period standard deviation of inflation, a variable it is not possible to measure sensibly over a five-year window.

${ }^{23}$ The experiments are based on the observation that, under the non-demographic null, plim $\hat{\beta}={ }_{x \boldsymbol{x}}{ }^{1} \boldsymbol{C o v}(\boldsymbol{X}, u)$,

where $\quad x^{1}$ is the relevant portion of the inverse second moment matrix for the explanatory variables. Using $\operatorname{Cov}\left(X_{i}, u\right)=x_{u}\left(X_{i}, u\right)$, the direction and magnitude of the asymptotic bias associated with any particular element of $\hat{\beta}$ can be determined given an assumed pattern of correlation between the explanatory variables and the disturbance term, and assumed values for the corresponding standard deviations. The Monte-Carlo experiments involve two steps. First, given estimates of $\quad x$ and $\quad$, I conduct a grid search over the possible parameter space describing $(\boldsymbol{X}, u)$ in order to identify the regions in which one might find "significant" coefficients of the hypothesized sign under the null. (Bias in the "wrong" direction identifies a region associated with type I rather than type II errors: failure to reject the null even when it is false.) 
For the fixed-effects model, a type II error for national savings or the CAB becomes more likely when the equation errors are negatively correlated with labor productivity growth, and positively correlated with relative investment prices. A type II error for investment becomes more likely given the opposite pattern of correlation. The experiments indicate that the probability of a type II error in a given equation remains relatively small, even in these "danger zones," unless the relevant correlations both exceed 0.2 in absolute value. ${ }^{24}$ For the pooled model, a type II error for any of the three equations becomes more likely when the equation errors are negatively correlated with both GROWTH and RPI. Again, the likelihood of a type II error appears relatively small for correlations below 0.2 in absolute value. $^{25}$

The lesson to draw from these Monte Carlo experiments depends importantly on one's priors. The natural procedure is to adjust the estimated significance levels downward according to the probability attached to the hypothesis that the relevant correlations lie near or beyond the "danger zones" described above. I can offer no direct evidence concerning the sign or magnitude of these correlations. However, it is generally accepted that high savings and investment rates should raise

Second, for various points in the "danger zone" identified, 5000 observations of artificial data following a MVN distribution are generated. These data are consistent with the non-demographic null, and with the observed covariance matrix for the RHS variables. Regressions relying on the artificial data are used to determine the distortion in the size of the relevant Ftests.

${ }^{24}$ Using a test with a nominal size of one percent, and setting both correlations equal to 0.2 in absolute value, the probability of a type II error is highest for the investment equation, at 11.6 percent. The probability that a type II error will occur in two or more equations is far smaller, at 2.1 percent. The probability of type II errors diminishes quickly with the strength of the assumed correlations: with both correlations equal to 0.16 , the probability falls to 5.8 percent for the investment equation, and to 0.6 percent for two or more equations.

${ }^{25}$ Relying on a test with a nominal size of one percent, and setting both correlations equal to 0.2 in absolute value, the probability of a type II error is again highest for the investment equation, at 11.9 percent. The probability of such an error in two or more equations is 6.0 percent. With both correlations equal to 0.16 , the probability of a type II error falls to 5.4 percent for the investment equation, and to 2.6 percent for two or more equations. 
productivity growth, at least outside the steady state. If this is indeed true, the fixed-effects results for savings and the pooled results for both savings and investment cannot be ascribed to simultaneity bias.

\section{The Future}

The findings reported above support a strong link between changes in national age distributions and the disposition of national income, suggesting that they lie behind secular movements savings, investment, and thus, in capital flows. Moreover, the results are broadly consistent with the implications of standard theoretical models concerning the relationship of age structure with these variables. This section concludes by considering the implications of the results for the direction and extent of capital flows during the early decades of the next century.

To gauge the pressure that expected changes in national age distributions can expected to exert on savings, investment and the $\mathrm{CAB}$, I construct out-of-sample projections based on the estimated agedistribution coefficients. The projections are ceteris paribus in nature, making no attempt to control for non-demographic influences on these variables. Although this represents a strong simplifying assumption, the results developed here provide no basis for specifying the paths of GROWTH, RPI or other potentially relevant explanatory variables. This limitation should be kept in mind in interpreting the projection results.

As the rule, the next 15 years should bring moderate to substantial declines in saving rates in the developed world (Table 7). Saving rates are projected to fall by less than one percentage point in the U.S. and UK, but by more than five percentage points in Germany, and six percentage points in Japan. It should be noted that these declines are projected for a period in which the effects of a rise in the proportion of elderly should be offset, at least in some measure, by a fall in the youth-dependency ratio and a rise in the share of prime-age adults. That saving is expected to decline is due in part to the aging of the non-elderly population, with an increasing proportion concentrated in the years of late middle age (55-64) at the expense of the broad middle of adult life (35-54).

The entry of the baby-boom cohort into its retirements years (beginning soon after 2010) should bring an acceleration of these trends. The projected decline in the saving rate between the years 2010 and 2025 stands at more than three percentage points for the OECD as a whole, although a 
several nations should experience declines of 4 to 5.5 percentage points. The cumulative decline between 1990 and 2025 would leave the developed world's average saving rate at about 16.5 percent of GDP. The U.S. saving rate is projected to fall to only 11.2 percent of GDP; Japan's saving rate, in spite of greater negative demographic pressure, is projected to remain above 25 percent of GDP.

As the developed world grays, the currently less developed world will mature. (Indeed, the share of prime-age adults among non-OECD nations is expected to rise by 4.4 percentage points by 2010, and a further 3.5 percentage points by 2025.) The likely result is a fairly substantial rise in saving rates over the next 15 years, ranging as high as nine percentage points of GDP, but with gains of two to five percentage points being more typical. The nations of sub-Saharan Africa represent an exception to this pattern because a significant decline in birth rates is yet to emerge. Saving rates are expected to rise only modestly for these countries.

Most of the developing world should see a further rise in saving rates during the following period (2010 to 2025), with gains of two to five percent being typical. Where birth rates have only recently peaked or not yet begun to decline (for example, in much of sub-Saharan Africa and in several Arab countries), age distributions will be moving toward the center. Here a rise in national savings amounting to several percentage points of GDP should be expected. The "four tigers" of the Pacific Rim (Hong Kong, Korea, Singapore and Taiwan), where birth rates began to decline rapidly by the 1970s, represent the major exception to this pattern. Here, populations will begin aging rapidly after 2010. The result should be a decline in national savings amounting to several percentage points of GDP between 2010 and 2025. A trend toward declining saving should also begin to emerge soon after 2010 for Thailand and a few advanced Latin American economies.

Does the projected decline in investment among OECD nations imply that its future labor will be working with a diminished capital stock? To derive a provisional answer, I rely on the real capital stock measures constructed by Summers and Heston (1995). Assume that the OECD's aggregate production technology is neoclassical, with labor-augmenting technical progress. A constant capitaloutput ratio (and thus, constant capital per effective worker) is maintained at the investment rate $\mathrm{i}$ which satisfies: $\mathrm{i}(\mathrm{Y} / \mathrm{K})^{*}=(\mathrm{n}+\mathrm{g}+\quad)$. I set the rate of labor-augmenting technical progress $(\mathrm{g})$ at two 
percent, and note that OECD labor-force growth (n) is expected to average approximately zero for the OECD by 2025. (This assumes that the labor-force participation rate for the 15-64 populations remain unchanged at its 1985-89 value). Given the distribution of the OECD capital stock between structures and machinery, and the sectoral depreciation rates used by Summers and Heston (1995, in the file descrip.doc), an investment rate of approximately 14.5 percent is required to maintain capital per effective worker at its 1990 level. The projected OECD investment rate of 15.5 percent in 2025 then implies a slightly more capital-rich factor mix than now exists.

As for the non-OECD world, an investment rate of only 11.0 percent is required to maintain capital per effective worker at its 1990 level (given expected labor-force growth, and again setting g at two percent). With investment rates projected to remain above 20 percent through 2025 , the capital intensity of production should rise continuously. As a result, demographic developments should tend to promote convergence between OECD and non-OECD labor productivity levels.

What do the projections imply for the gap between savings and investment, the CAB? The results reported in Table 7 follow a striking pattern. For the developed world, investment should decline more than savings, so that external balances should be subject to favorable demographic pressure. The average increase in the CAB (relative to 1990) should amount to 3.2 percent of GDP by 2010, before subsiding to 1.7 percent of GDP by 2025. For developing countries, investment should rise less than savings, so that the $\mathrm{CAB}$ should be subject to favorable demographic pressure for these countries as well. ${ }^{26}$ These gains are projected to be substantial, topping 6 percent of national income in many countries, with about half of the increase occurring after 2010.

[Table 7 about here.]

An important caveat should be kept in mind. Consider that the coefficients of the demographic variables are meant to capture how national savings and investment rates evolve in response to changing national age distributions. Yet the estimates are also influenced by the changes in the world

${ }^{26}$ Taylor (1995) uses a similar projection method to find that Latin American CABs should be subject to upward demographic pressure by the early decades of the next century. 
age distribution which took place during the sample period. The effects of a given change in a country's own age distribution on, say, its current balance might be different when it occurs against the backdrop of a world population which is growing steadily older rather than steadily younger. Out-ofsample projections cannot capture the general equilibrium effects of a novel pattern of global demographic change.

Even so, it is possible to draw certain tentative conclusions by recalling that the world as a whole is a closed economy. A declining youth-dependency ratio (and the resulting slowdown in laborforce growth) should act as a brake on world investment demand, while the increase in the share of prime-age adults should swell the supply of savings. The equilibrium of the global capital market should then lead to lower real interest rates. The reduction in world interest rates would in turn moderate the increase in saving and decline in investment demand. Indeed, the projections imply this much in that they indicate — of course, counterfactually—-that a world current account surplus will develop by 2010. As a result, the tendency for current balances to improve in the developing world (as implied by the projections) would be muted.

\section{APPENDIX}

(A.1) Data Sources. Nominal national accounts data are reconstructed from the Penn World Tables (Mark 5.6), available on diskette from the NBER. An exception here concerns net factor income (NFI). Although an NFI series is reported in the Penn World Tables, it extends only back to 1970 and does not appear fully reliable. As a result, NFI shares are calculated using data from International Financial Statistics (IMF tape). The CAB is measured as the sum of the trade balance and net factor income. National savings is measured by adding gross investment to this total. Note that the measures used here for both national savings and the $\mathrm{CAB}$ exclude private and official transfers, and, thus, are not strictly correct. These definitions were chosen because data concerning transfers come from balance-of-payments sources generally unavailable before 1970. The difference in measured savings or $\mathrm{CAB}$ shares is almost always quite small, and appears not to affect the results. The relative price of investment goods (RPI) and the growth rate of output per worker (GROWTH) are also derived from 
the Penn World Tables. Demographic data are from the United Nations (1991). Taiwan represents the sole exception to the above, with national accounts and demographic data derived from the Statistical Yearbook of the Republic of China, various issues. The additional variables used to implement EBA are generally from Barro and Lee (1994). However, U.S. interest rates and consumer price inflation were measured using data from International Financial Statistics.

(A.2) Polynomial Representation of the Age Distribution. Consider the regression specification:

$$
s_{t}=+x_{t} \beta+{ }_{1} p_{1 t}+{ }_{2} p_{2 t}+\ldots+p_{j t}+u_{t}
$$

where $s_{t}$ is the dependent variable, $\mathbf{x}_{\mathbf{t}}$ a vector of explanatory variables and $\mathrm{p}_{1 \mathrm{t}}, \ldots, \mathrm{p}_{\mathrm{Jt}}$ represent the shares of the population in $\mathrm{J}$ age groups. Constraining the coefficients of the population shares to lie along a third-order polynomial means that they are constructed as: $j=0+{ }_{1} j+{ }_{2} j^{2}+{ }_{3} j^{3}$. We can then rewrite the regression specification as:

$$
s_{t}=+\boldsymbol{x}_{\boldsymbol{t}} \beta+{ }_{0} \sum_{i=1}^{J} p_{j, t}+{ }_{1} \sum_{i=1}^{J} j p_{j, t}+{ }_{2} \sum_{i=1}^{J} j^{2} p_{j, t}+{ }_{3} \sum_{i=1}^{J} j^{3} p_{j, t}+u_{t}
$$

Now impose the additional restriction that the coefficients of the age distribution variables sum to zero, that is, that $\sum_{j}=0$. This implies the following relationship among ${ }_{0},{ }_{1},{ }_{2}$ and ${ }_{3}$ :

$$
{ }_{0} J+{ }_{1} \sum_{j=1}^{J} j+{ }_{2} \sum_{j=1}^{J} j^{2}+{ }_{3} \sum_{j=1}^{J} j^{3}=0 \Rightarrow \quad 0=\left({ }_{1} / J\right) \sum_{j=1}^{J} j \quad\left({ }_{2} / J\right) \sum_{j=1}^{J} j^{2} \quad\left({ }_{3} / J\right) \sum_{j=1}^{J} j^{3}
$$

Thus, our final regression specification is given by:

$$
\text { (A.2.4) } i_{t}=+\boldsymbol{x}_{t} \beta+1\left(\sum_{j=1}^{J} j p_{j, t}(1 / J) \sum_{j=1}^{J} j\right)+2\left(\sum_{j=1}^{J} j^{2} p_{j, t}(1 / J) \sum_{j=1}^{J} j^{2}\right)+3\left(\sum_{j=1}^{J} j^{3} p_{j, t}(1 / J) \sum_{j=1}^{J} j^{3}\right)+u
$$

The specification above summarizes the information contained in the age distribution according to three variables (which I call $\mathrm{D}_{1}, \mathrm{D}_{2}$ and $\mathrm{D}_{3}$ ) which are, in effect, geometric averages of the population age shares. Given the estimated coefficients, ${ }_{1}, \quad{ }_{2}$ and ${ }_{3}$, we can find ${ }_{0}$ using Equation (A.2.3). The implicit ${ }_{j}$ can then be recovered as a function of the four coefficients. 


\section{REFERENCES}

Barro, R. AND J. LeE, Data Set for a Panel of 138 Countries (1994), available on diskette from R. Barro at Harvard University, or via FTP from the NBER.

Coale, A. AND E. Hoover, Population Growth and Economic Development in Low-Income Countries (Princeton: Princeton Univ. Press, 1958).

Collins, S., "Savings Behavior in Ten Developing Countries," in B. Bernheim and J. Shoven, eds., National Saving and Economic Performance (Chicago: Univ. of Chicago Press, 1991), 349373.

Cutler, D; Poterba, J.; Sheiner, L.; AND L. Summers, “An Aging Society: Opportunity or Challenge?," Brookings Papers on Economic Activity (no. 1, 1990), 1-73.

DAVIDSON, R. AND J. MACKINNON, Estimation and Inference in Econometrics (New York: Oxford University Press, 1993).

Deaton, A., Understanding Consumption (Oxford: Clarendon Press, 1992).

FAIR, R. AND K. DomingueZ, "Effects of the Changing U.S. Age Distribution on Macroeconomic Equations," American Economic Review 81 (1991), 1276-1294.

FRY, M. AND A. MASON, "The Variable Rate-of-Growth Effect in the Life-Cycle Model," Economic Inquiry 20 (1982), 426-442.

Gersovitz, M., "Saving and Development," in H. Cheney and T. Srinivason, eds., Handbook of Development Economics (Amsterdam: North Holland, 1988), 381-424.

Goldberger, A., "Dependency Rates and Savings Rates: Further Comment." American Economic Review 63 (1973), 232-233.

GreEne, W., Econometric Analysis (New York: Macmillan Publishing Company, 1993).

HAMmER, J. (1985). "Population Growth and Saving in LDCs: A Survey," World Development 14 (1986), 579-591.

Heston, A. And R. Summers, Penn World Table, Mark 5.6 (1995), diskette available from the National Bureau of Economic Research, Cambridge, Massachusetts. 
Higgins, M. AND J. WiLliAMSON, “Asian Demography and Foreign Capital Dependence,” NBER Working Paper No. 5580 (1996).

LAL, D., "World Savings and Growth in Developing Countries," Discussion Papers in Economics No. 91-05, University College, London (1991).

LEFF, N., "Dependency Rates and Savings Rates," American Economic Review 59, 886-896.

LeVIne, R. AND D. Renelt, “A Sensitivity Analysis of Cross-Country Growth Regressions,” American Economic Review 82 (1992), 942-963.

MASOn, A., "National Saving Rates and Population Growth: A New Model and New Evidence," in D. Johnson and R. Lee, eds., Population Growth and Economic Development: Issues and Evidence (Madison: Wisconsin University Press, 1987), 523-560.

MASON, A., "Saving, Economic Growth and Demographic Change," Population and Development Review 14 (1988), 113-144.

Newey, W. And K. WeSt, “A Simple, Positive Semidefinite, Heteroskedasticity and Autocorrelation Consistent Covariance Matrix,” Econometrica 55 (1987), 703-708.

RAM, R., "Dependency Rates and Aggregate Savings: A New International Cross-Section Study," American Economic Review 72 (1982), 537-544.

SACHS, J. AND A. WARNER, "Economic Reform and the Process of Global Integration," Brookings Papers on Economic Activity (no. 1, 1995), 1-118.

SHEA, J., "Instrument Relevance in Multivariate Linear Models: A Simple Measure," NBER Technical Working Paper No. 193 (1996).

TAYLOR, A., "Domestic Saving and International Capital Flows Reconsidered," NBER Working Paper No. 4892 (1994).

TAYLOR, A., "Debt, Dependence and the Demographic Transition: Latin America into the Next Century," World Development 23 (869-879).

TAYLOR, A. AND J. Williamson, "Capital Flows to the New World as an Intergenerational Transfer," Journal of Political Economy 102 (1994), 348-369. 
United Nations, Global Estimates and Projections of Populations by Age and Sex (New York:

United Nations, 1991).

WeIL, D., "The Saving of the Elderly in Micro and Macro Data," Quarterly Journal of Economics 109 (1994).

Williamson, J., "Human Capital Deepening, Inequality and Demographic Events Along the Pacific Rim," in O. Ogawa, G. Jones and J. Williamson, eds., Human Resources and Development Along the Asia Pacific Rim (Singapore: Oxford University Press, 1993). 
Table 1

FIXED-EFFECTS ESTIMATES
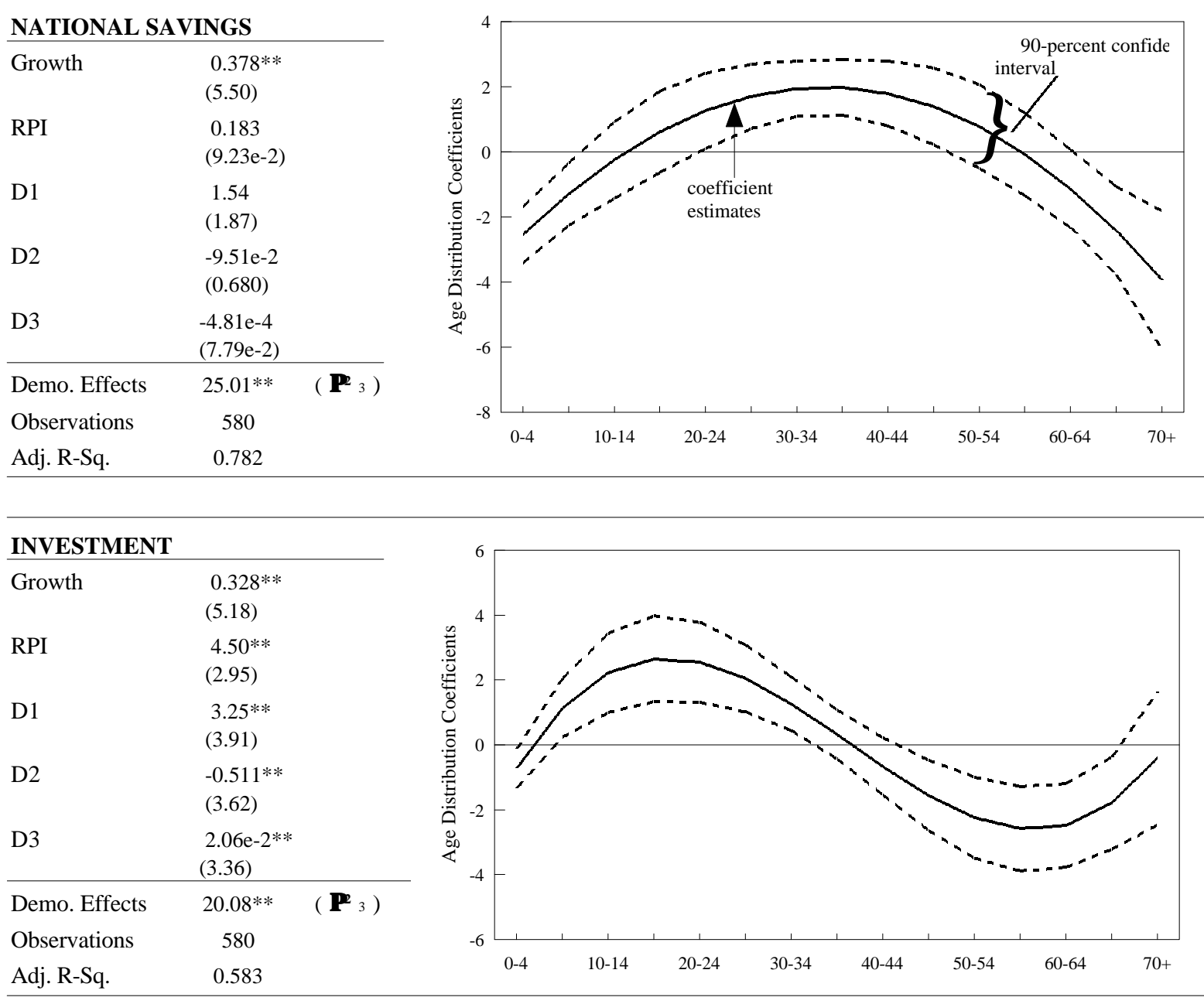

\section{CURRENT ACCOUNT BALANCE}

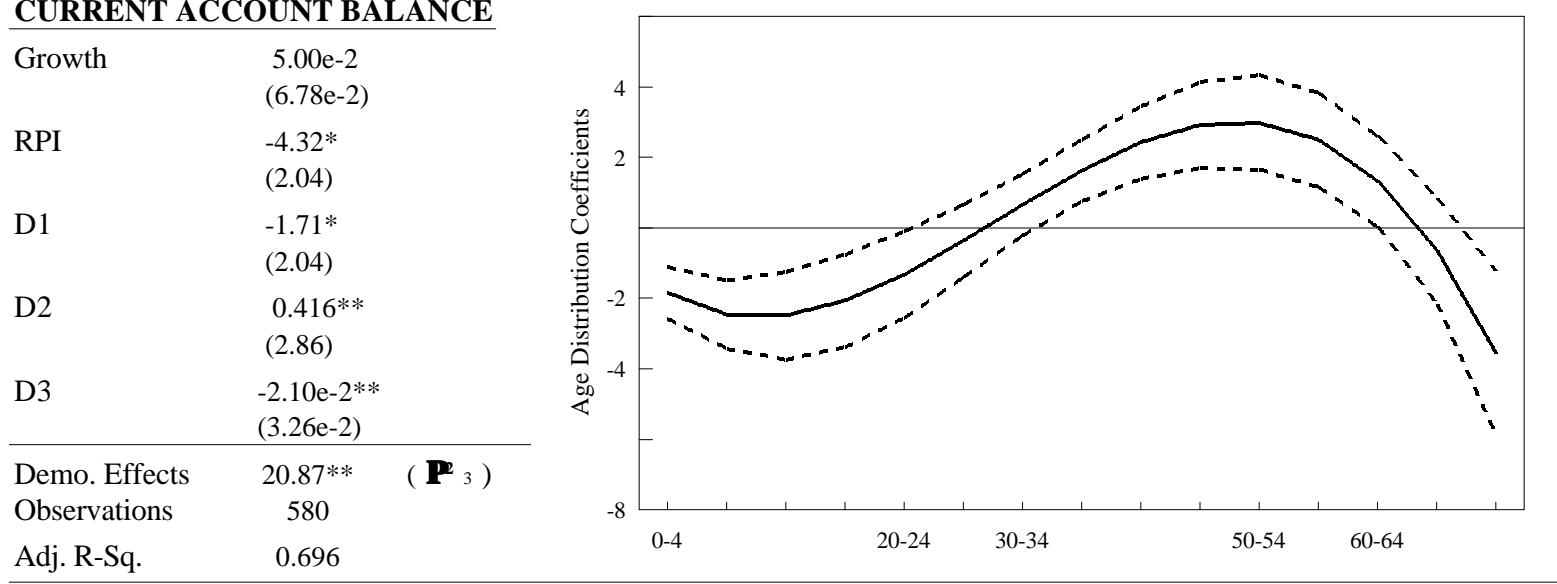

\section{NOTES}

1. The estimated equations also include 100 country-specific dummy variables (not reported).

2. Asymptotic absolute t-statistics are in parentheses. $*$ for five-percent significance, $* *$ for one-percent significance.

3. Method of estimation: ordinary least squares, with standard errors corrected for contemporaneous heteroskedasticity and first-order serial correlation.

4. The age-distribution coefficients represent the change in the dependent variable associated with a unit change in the corresponding log population age shares. 
Table 2

FIXED-EFFECTS MODEL WITH INTERACTIVE TERMS

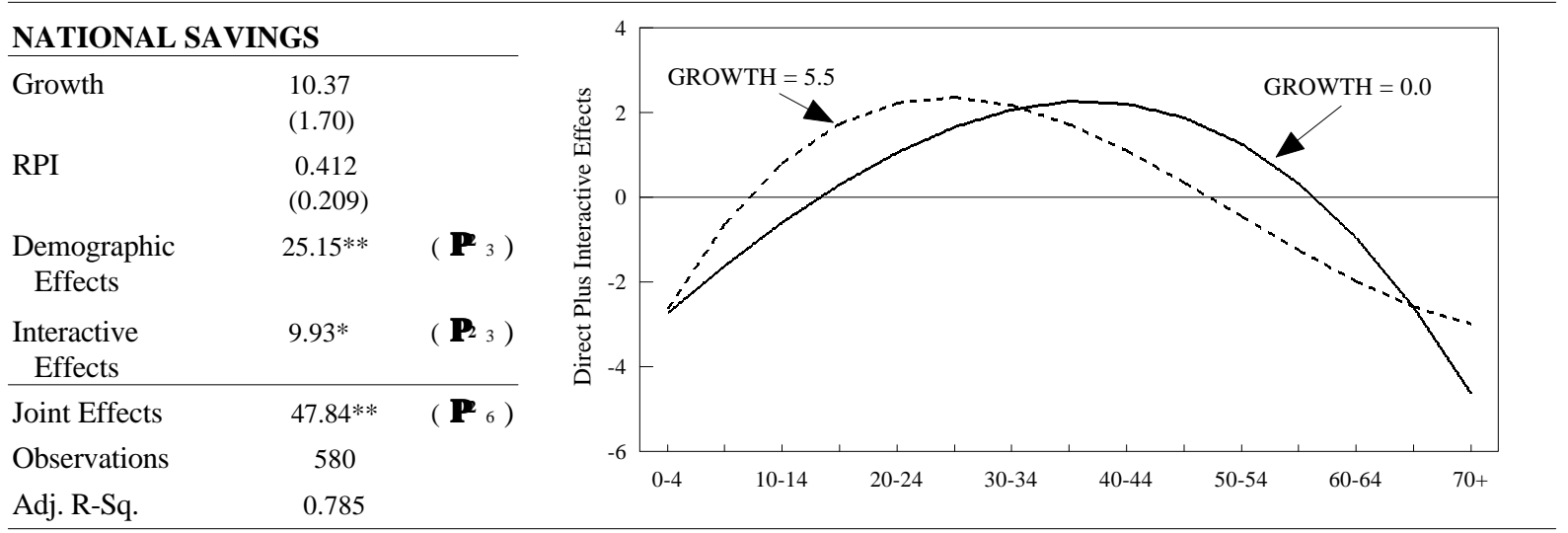

NOTES

1. See notes to Table 1 for estimation details. 
Table 3

\section{DEMOGRAPHIC PRESSURE IN THE PAST}

Representative OECD Countries

\begin{tabular}{lccccccc} 
Country & Period & Saving & Investment & CAB & Young & Prime & Old \\
\hline Canada & $1960-64-1985-89$ & 4.2 & 1.1 & 3.1 & -12.2 & 7.2 & 3.2 \\
Germany & $1950-54-1965-69$ & -2.2 & -0.3 & -1.9 & 0.3 & -2.4 & 2.7 \\
Japan & $1950-54-1980-84$ & 5.6 & -1.5 & 7.1 & -12.0 & 11.6 & 4.4 \\
UK & $1950-54-1970-74$ & -2.2 & 0.6 & -2.8 & 1.3 & -5.7 & 2.4 \\
U.S.A. & $1960-64-1985-89$ & 2.5 & 2.1 & 0.4 & -9.2 & 4.6 & 2.9 \\
\hline
\end{tabular}

Representative Non-OECD Countries

\begin{tabular}{lccccccc} 
Country & \multicolumn{1}{c}{ Period } & Saving & Investment & CAB & Young & Prime & Old \\
\hline Algeria & $1950-54-1970-74$ & -7.3 & -2.8 & -4.6 & 7.5 & -6.2 & -0.1 \\
Bangladesh & $1950-54-1980-84$ & -9.0 & -2.6 & -6.4 & 7.9 & -8.3 & -0.4 \\
Brazil & $1960-64-1985-89$ & 5.4 & 4.4 & 1.0 & -7.8 & 4.2 & 1.4 \\
India & $1965-69-1985-89$ & 1.8 & 2.1 & -0.3 & -3.2 & 0.7 & 0.7 \\
Indonesia & $1970-74-1985-89$ & 3.0 & 2.6 & 0.4 & -4.7 & 1.7 & 0.6 \\
Kenya & $1950-54-1985-89$ & -11.1 & -3.5 & -7.6 & 9.3 & -8.2 & -1.0 \\
Korea & $1960-64-1985-89$ & 10.1 & 4.7 & 5.4 & -14.3 & 9.6 & 1.2 \\
Mexico & $1970-74-1985-89$ & 5.3 & 3.7 & 1.6 & -7.4 & 3.8 & 0.3 \\
Nigeria & $1960-64-1985-89$ & -1.5 & -0.3 & -1.2 & 1.7 & -1.5 & 0.2 \\
Thailand & $1965-69-1985-89$ & 7.9 & 5.1 & 2.8 & -11.4 & 5.9 & 0.8 \\
\hline
\end{tabular}

\section{Notes}

1. The middle columns report the demographically-induced change in each variable as a share of GDP. The remaining columns refer to changes in age shares.

2. The periods reported contain the maximum demographic swing in each country's savings rate.

3. Young: 0-14. Prime: 25-59. Old: 65 and older. 
Table 4

POOLED ESTIMATES
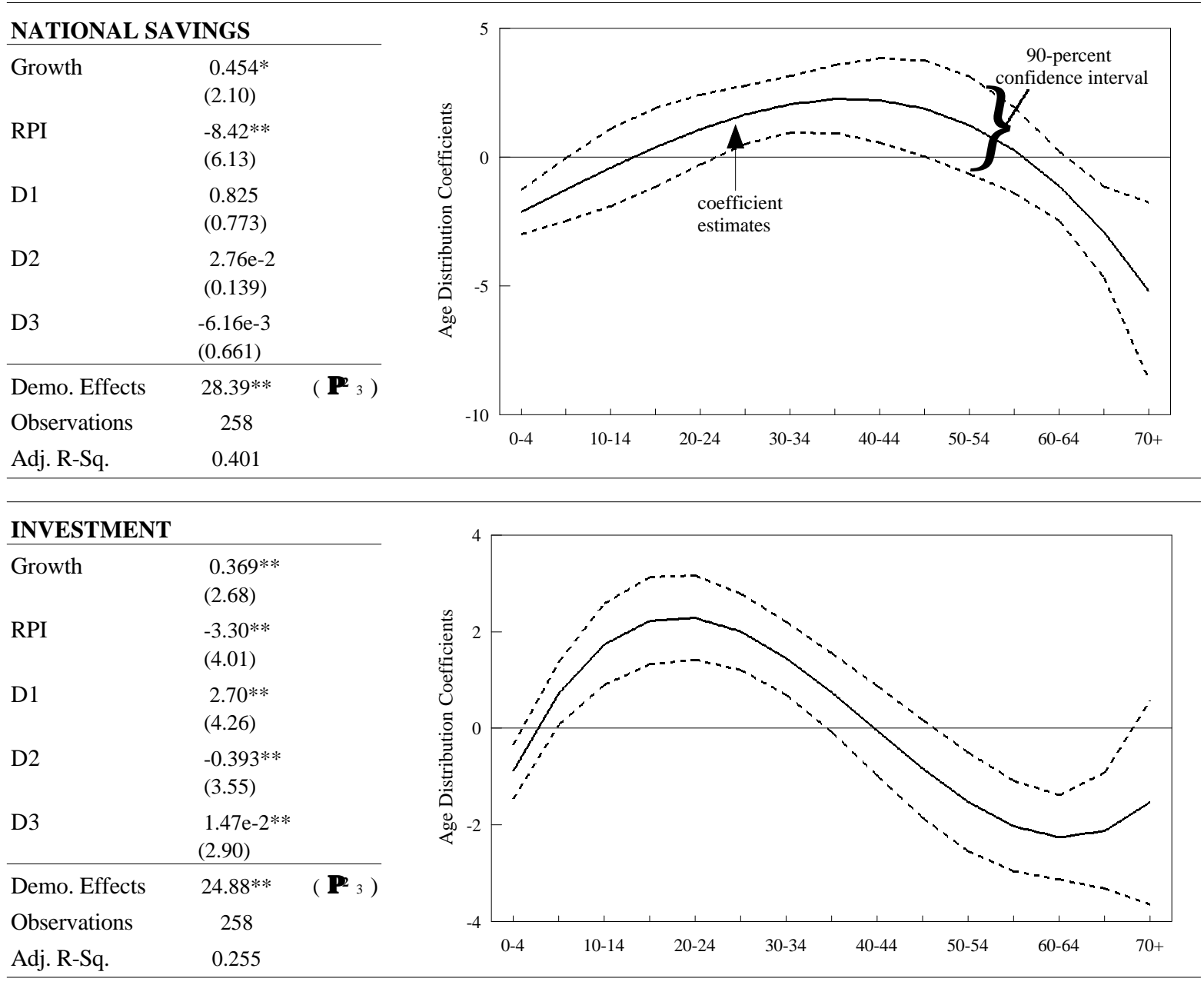

\section{CURRENT ACCOUNT BALANCE}

\begin{tabular}{lll}
\hline Growth & $\begin{array}{l}7.01 \mathrm{e}-2 \\
(0.336)\end{array}$ \\
& $\begin{array}{l}\text {-5.13** } \\
\text { RPI }\end{array}$ & $(4.06)$ \\
& -1.85 \\
D1 & $(1.86)$ & \\
& $0.414^{*}$ & \\
D2 & $(2.22)$ & \\
& $-2.05 \mathrm{e}-2^{*}$ & \\
D3 & $(2.36 \mathrm{e}-2)$ & \\
& $16.58^{* *}$ & $\left(\mathbf{P}^{2}{ }_{3}\right)$ \\
Demo. Effects & 258 & \\
Observations & & \\
Adj. R-Sq. & 0.214 &
\end{tabular}

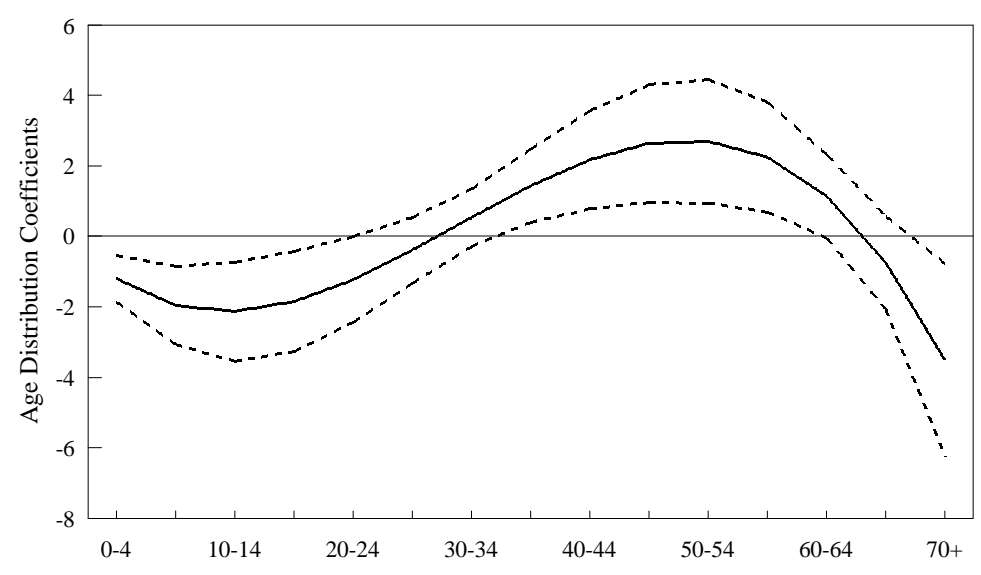

\section{NOTES}

1. The estimated equations also include dummy variables for the three time periods (not reported).

2. Asymptotic absolute t-statistics are in parentheses. $*$ for five-percent significance, $* *$ for one-percent significance.

3. Method of estimation: ordinary least sqaures, with standard errors corrected for contemporaneous heteroeskedasticity.

unit change in the corresponding log population age shares. 
Table 5

POOLED MODEL WITH INTERACTIVE EFFECTS

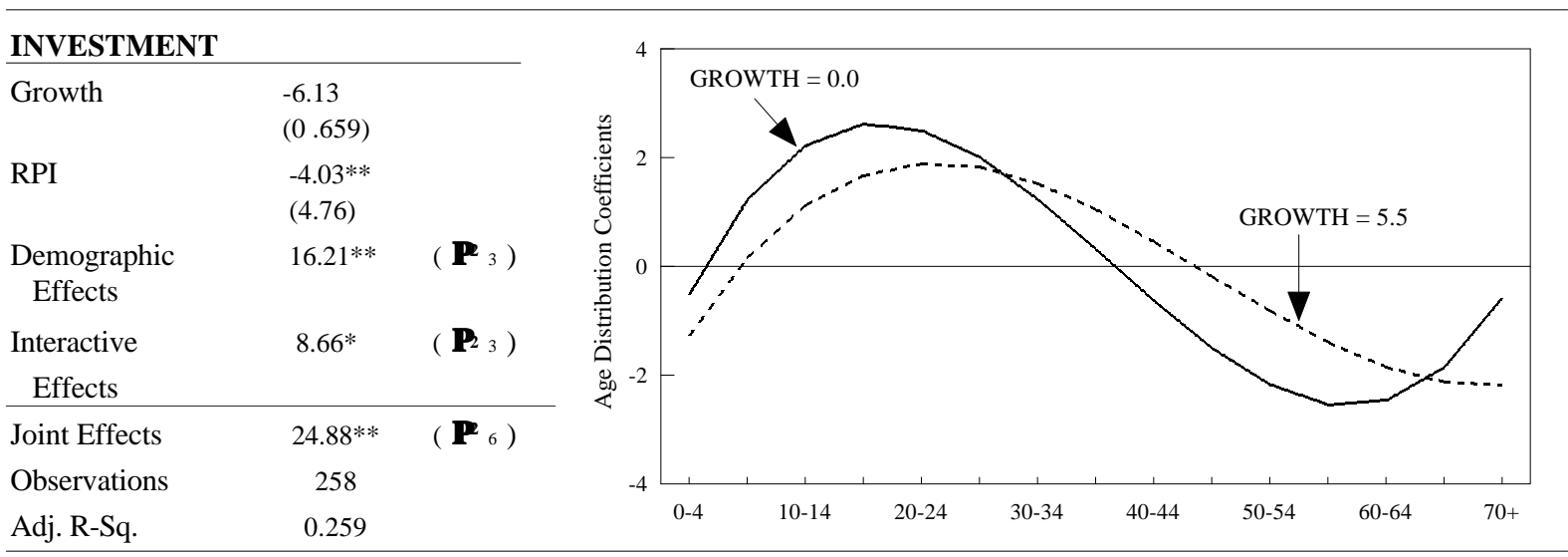

\section{NOTES}

1. See notes to Table 4 for estimation details.

2. The lines show the combined direct and interactive effects associated with the labeled productivity growth rates. 
Table 6

OPENNESS AND DEMOGRAPHIC EFFECTS

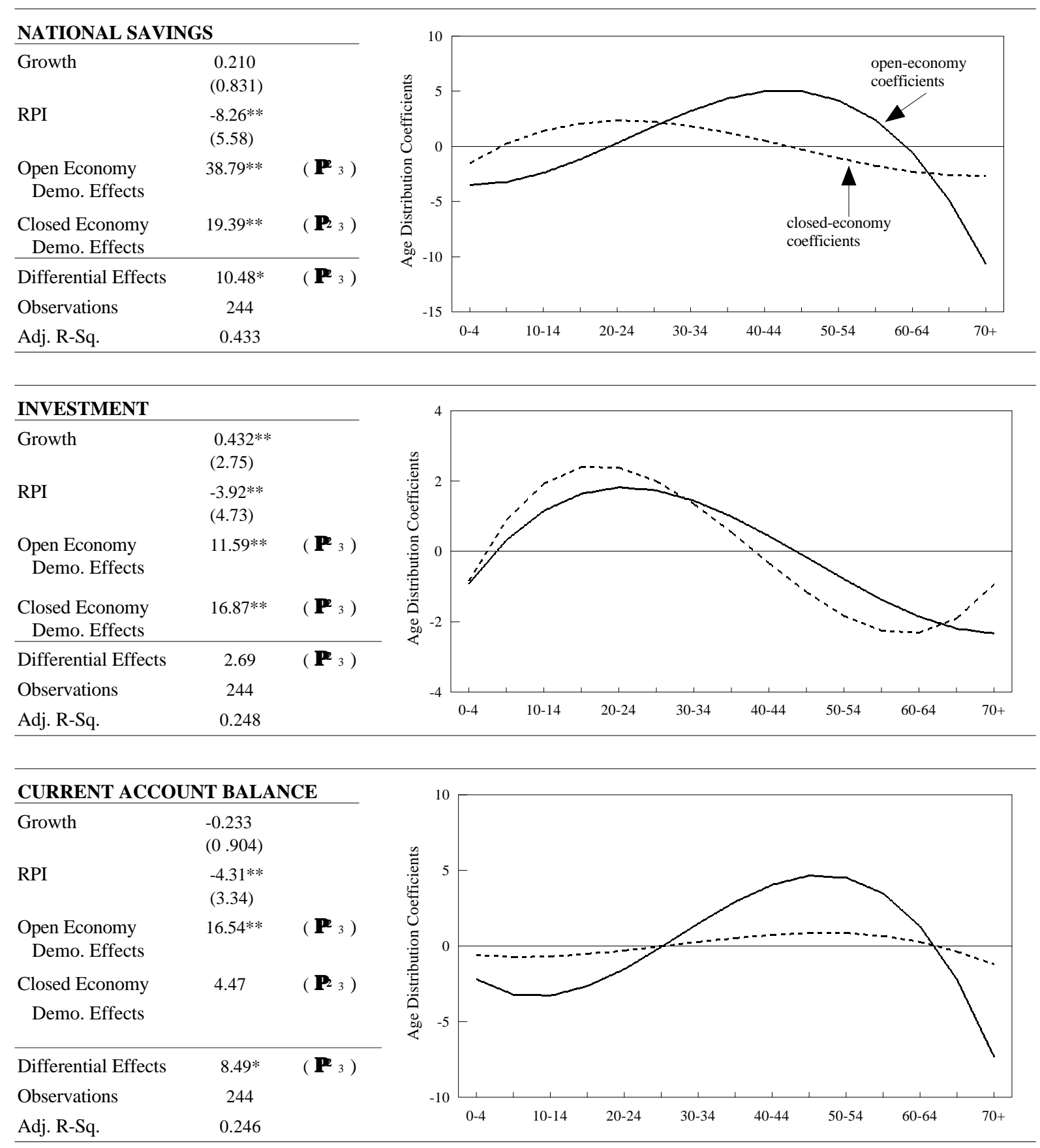

NOTES

1. See notes to Table 4 for estimation details. 
Table 7

DEMOGRAPHIC PRESSURE IN THE FUTURE

Representative OECD Countries

\begin{tabular}{lcccrrrr} 
Country & Year & Saving & Investment & CAB & Young & Prime & Old \\
\hline Canada & 2010 & -2.3 & -6.3 & 4.0 & -4.7 & 0.4 & 3.0 \\
& 2025 & -7.0 & -8.2 & 1.2 & -7.2 & -5.4 & 9.8 \\
\multirow{2}{*}{ Germany } & 2010 & -5.1 & -6.2 & 1.1 & -0.8 & -2.0 & 5.0 \\
& 2025 & -9.0 & -10.3 & -1.3 & -0.9 & -7.1 & 8.7 \\
\multirow{2}{*}{ Japan } & 2010 & -6.2 & -7.7 & -1.5 & -1.2 & -4.1 & 7.9 \\
& 2025 & -9.3 & -11.6 & -2.3 & -3.5 & -5.4 & 12.2 \\
\multirow{2}{*}{ UK } & 2010 & -0.9 & -4.0 & 3.1 & -1.0 & 1.2 & 0.3 \\
& 2025 & -4.0 & -5.7 & 1.7 & -1.7 & -1.2 & 4.0 \\
\multirow{2}{*}{ U.S.A. } & 2010 & -0.8 & -5.3 & 4.5 & -2.9 & 1.6 & 0.9 \\
& 2025 & -4.6 & -6.5 & 1.9 & -3.6 & -3.5 & 7.2 \\
\hline OECD & 2010 & -2.1 & -5.3 & 3.2 & -2.2 & 1.4 & 2.3 \\
Average & 2025 & -5.8 & -7.5 & 1.7 & -3.4 & -2.1 & 7.1 \\
\hline
\end{tabular}

Representative Non-OECD Countries

\begin{tabular}{|c|c|c|c|c|c|c|c|}
\hline Country & Year & Saving & Investment & CAB & Young & Prime & Old \\
\hline \multirow[t]{2}{*}{ Algeria } & 2010 & 8.6 & 3.3 & 5.3 & -7.9 & 9.7 & 0.2 \\
\hline & 2025 & 15.4 & 4.1 & 11.3 & -18.3 & 17.1 & 1.8 \\
\hline \multirow[t]{2}{*}{ Bangladesh } & 2010 & 7.4 & 2.8 & 4.6 & -7.2 & 7.6 & 0.2 \\
\hline & 2025 & 14.3 & 3.6 & 10.7 & -17.0 & 15.1 & 1.8 \\
\hline \multirow[t]{2}{*}{ Brazil } & 2010 & 5.0 & -0.2 & 5.2 & -7.0 & 5.8 & 1.6 \\
\hline & 2025 & 5.5 & -1.3 & 6.8 & -10.6 & 7.1 & 4.6 \\
\hline \multirow{2}{*}{ India } & 2010 & 4.3 & 1.3 & 3.0 & -6.1 & 5.0 & 1.4 \\
\hline & 2025 & 7.2 & 0.4 & 6.8 & -13.2 & 10.4 & 3.7 \\
\hline \multirow[t]{2}{*}{ Kenya } & 2010 & 2.6 & 0.4 & 2.2 & -2.3 & 2.9 & -0.5 \\
\hline & 2025 & 10.3 & 4.4 & 5.9 & -10.2 & 7.5 & 0.1 \\
\hline \multirow[t]{2}{*}{ Korea } & 2010 & 1.3 & -5.8 & 7.1 & -6.3 & 8.0 & 3.9 \\
\hline & 2025 & -2.9 & -9.6 & 6.7 & -9.0 & 3.3 & 9.7 \\
\hline \multirow[t]{2}{*}{ Mexico } & 2010 & 8.0 & 0.7 & 7.3 & -8.5 & 10.4 & 1.8 \\
\hline & 2025 & 9.1 & -1.2 & 10.3 & -12.3 & 12.4 & 4.4 \\
\hline \multirow[t]{2}{*}{ Nigeria } & 2010 & 2.6 & 2.5 & 0.1 & -3.4 & 1.5 & 0.3 \\
\hline & 2025 & 10.2 & 6.0 & 4.2 & -12.2 & 8.2 & 1.0 \\
\hline \multirow[t]{2}{*}{ Indonesia } & 2010 & 6.4 & 1.1 & 5.3 & -9.6 & 9.6 & 2.5 \\
\hline & 2025 & 6.9 & -2.1 & 9.0 & -13.1 & 12.5 & 5.2 \\
\hline \multirow[t]{2}{*}{ Thailand } & 2010 & 5.8 & -2.0 & 7.8 & -8.0 & 11.3 & 2.3 \\
\hline & 2025 & 4.8 & -4.6 & 9.4 & -11.6 & 9.6 & 6.2 \\
\hline Non-OECD & 2010 & 3.7 & 0.5 & 3.2 & -4.9 & 4.4 & 0.8 \\
\hline Average & 2025 & 7.0 & -1.3 & 5.7 & -10.7 & 7.9 & 2.9 \\
\hline
\end{tabular}

Notes

1. All variables refer to changes relative to 1985-89.

2. The OECD and non-OECD averages are unweighted. OECD membership is evaluated as of 1990 . 